Brit. J. prev. soc. Med. (1961), 15, 68

\title{
DIAGNOSTIC PRECISION AS A FACTOR IN MALE
}

\section{MORTALITY DATA}

\author{
BY \\ G. WYNNE GRIFFITH \\ AND \\ G. A. V. MORGAN \\ From the County Health Department, Anglesey
}

The work described in this paper started from an observation by Krasnow (1955) that mortality from cancer of the digestive tract was correlated with that from arteriosclerotic heart disease among males in the United States of America in the age range 65-69 years. The kind of association noted by Krasnow is illustrated in Fig.1(opposite). A preliminary examination of some of the data for England and Wales appeared to show that a similar correlation might exist in this country. For instance, it was found that the age-standardized mortality for males from coronary disease in the counties of England and Wales for 1950-1952 correlated to the extent of +0.26 with the mortality from cancer of the stomach. (This is significant at the conventional level of 0.05 ). Such a finding was unexpected, if only because the two causes of death show opposite gradients through the social classes. When the data were standardized for variation in the social class structure of the counties, the correlation became $+0.32(p=0.01)$. This result suggested that an examination of the available data to discover how other causes of death were correlated might prove of interest.

The associations of diseases have not been extensively studied, but among recent work might be mentioned that of Watkinson (1958), who found in post mortem material that coronary disease occurred more commonly in cases of chronic peptic ulceration than in his "controls", of Elkeles (1957) and Dungal and Benediktsson (1958), who found that gastric cancer was negatively associated with atheromatosis, and of Stocks (1959), who showed that mortality from lung cancer was correlated with that from bronchitis in 58 county boroughs of England and Wales. A negative finding was reported by Abbatt and Lea (1957), who showed in a series of 691 cases that leukaemia and respiratory tuberculosis displayed no association. Acheson (1960) has studied the correlations between mortality from cerebrovascular lesions, hypertensive disease, and coronary disease in the Irish Republic and compared these with the corresponding correlations between the Irish rates and those of fifteen other countries.

A table of correlation coefficients specifying the associations which exist between all possible pairs of a group of variables may be analysed further by the methods of factor analysis which have been extensively developed in psychometric work. Factor analysis is essentially an exploratory technique which aims at discovering some underlying order among a group of interdependent variables. The independent factors which emerge from the analys is may prove to be recognizable as physical, social, or other entities, but even where this is not so the factors may nonetheless indicate the existence of unsuspected relationships.

\section{Materials AND Methods}

A preliminary analysis was made using male mortality rates (uncorrected for age) for 25 of the main causes of death for the 4 years 1950-1953 in each of the geographical counties of England and Wales. In addition, variables were included in the analysis to represent the degree of urbanization, the age-structure of the male population, the social-class distribution, and the degree of overcrowding at the 1951 Census for each of the counties. Productmoment correlation coefficients were then calculated for all these variables and the matrix of correlation coefficients was analysed by the centroid method (Thurstone, 1947). The loadings of the "social" variables on each factor were obtained by a method suggested by Vernon (1958). The results (not reproduced here) were, in our opinion, of sufficient interest to warrant further work on these lines.

For a subsequent analysis we were greatly helped by Mr. Alan Kirk of the Liverpool University 


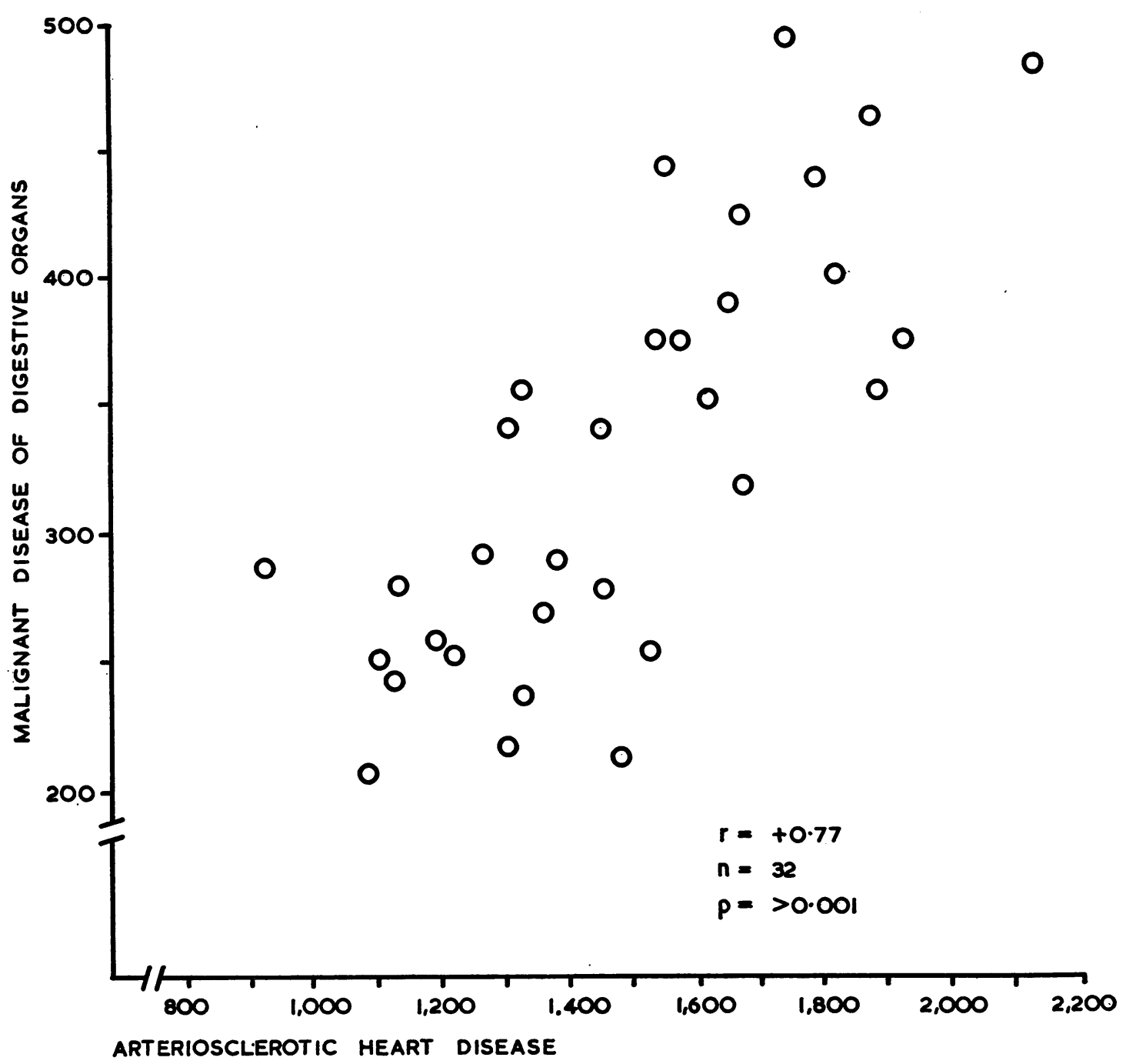

Fig. 1.-Correlation between mortality rates per 100,000 in 32 States of U.S.A. from malignant disease of the digestive organs and peritoneum and arteriosclerotic heart desease. White males aged 65-74 years, 1949-1951. (Source: Vital Statistics-Special Reports, Vol. 49 , Nos. 18 and 36. U.S. Dept. of Health, Education, and Welfare, Washington, 1959).

Computer Laboratory. The data used for this analysis were the number of deaths at all ages by cause during the 4 years $1950-1953$ in the administrative areas of England and Wales. The administrative areas comprise the counties excluding London (61), the county boroughs (83), and the metropolitan boroughs (29)-a total of 173. These vary considerably in size from the City of London with a population of some 5,000 to the county of Middlesex with 21 million. We decided to discard the data for six areas each of less than 40,000 population at the 1951 Census, leaving 167 areas for inclusion in the analysis. In addition to the number of deaths by causes, the values for each area for a number of " social" variables were included. Table I (overleaf) gives the detailed rubric for the variables, together with the source of the data. The values of each variable were transferred to punchcards which were then used in a computer with a programme written for a $40 \times 40$ correlation table taking out Principal Components (Hotelling, 1933). This method takes out the maximal amount of variance at each step so that successive factors normally account for decreasing amounts of variance. 
TABLE I

DATA USED IN THE ANALYSIS

I. Disease Variables*

\begin{tabular}{|c|c|c|c|}
\hline Symbol & Description & & $\begin{array}{l}\text { International } \\
\text { List Number }\end{array}$ \\
\hline $\begin{array}{l}\mathbf{A} \\
\mathbf{B} \\
\mathbf{C} \\
\mathbf{D} \\
\mathbf{E} \\
\mathbf{F} \\
\mathbf{G} \\
\mathbf{H} \\
\mathbf{I} \\
\mathbf{J} \\
\mathbf{K} \\
\mathbf{L} \\
\mathbf{M} \\
\mathbf{N} \\
\mathbf{O} \\
\mathbf{P} \\
\mathbf{Q} \\
\mathbf{R} \\
\mathbf{S} \\
\mathbf{T} \\
\mathbf{U} \\
\mathbf{V}\end{array}$ & 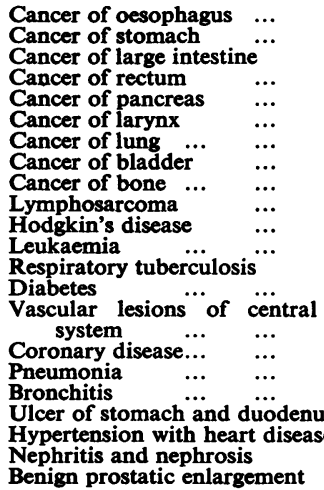 & 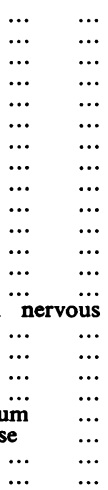 & $\begin{array}{c}150 \\
151 \\
153 \\
154 \\
157 \\
161 \\
162-163 \\
181 \\
196 \\
200 \\
201 \\
204 \\
001-008 \\
260 \\
330-334 \\
420 \\
490-493 \\
500-502 \\
540-541 \\
440-443 \\
590-594 \\
610\end{array}$ \\
\hline
\end{tabular}

II. "Social" Variablest

\begin{tabular}{|c|c|}
\hline Symbol & Variable \\
\hline $\begin{array}{l}(a) \\
(b) \\
(d) \\
(e) \\
(f)\end{array}$ & $\begin{array}{l}\text { Number of males at ages } 55-64 \\
\text { Number of males at ages 65-74 } \\
\text { Number of males at ages 75-84 } \\
\text { Number of males at ages } 85 \text { and over } \\
\text { Density of population (persons per acre) } \\
\text { Overcrowding (percentage of families living at density }\end{array}$ \\
\hline $\begin{array}{l}(g) \\
(h) \\
(j)\end{array}$ & $\begin{array}{l}\text { Percentage of occupied males in Social Classes I-II } \\
\text { Percentage of occupied males in Social Class III } \\
\text { Percentage of occupied males in Social Classes IV-V } \\
\text { Percentage males aged } 25 \text { and over with terminal }\end{array}$ \\
\hline $\begin{array}{l}(k) \\
(m) \\
(n)\end{array}$ & $\begin{array}{l}\text { Proportion of male population born in England } \\
\text { Proportion of male population born in Wales } \\
\text { Proportion of male population born in Scotland } \\
\text { Proportion of male population born in Northern } \\
\text { Ireland }\end{array}$ \\
\hline $\begin{array}{l}(o) \\
(p) \\
(q)\end{array}$ & $\begin{array}{l}\text { Proportion of male population born in Irish Republic } \\
\text { Proportion of male population born in Commonwealth } \\
\text { and Colonies } \\
\text { Proportion of male population born in Foreign } \\
\text { countries }\end{array}$ \\
\hline
\end{tabular}

- For each area the number of male deaths at all ages for each cause of death in 1950-1953 was taken from the Registrar General's Annual Review of England and Wales, Tables, Medical.

+ All data refer to 1951 Census (except for $f$ ) and are taken from the various Census Reports of the Registrar General for England and Wales published by H.M.S.O., London.

It accounts exactly if all factors are extracted for the "scores" (e.g. mortality rates) being analysed, but does not necessarily reproduce the correlations so closely as some other methods of factor analysis. Some results of this analysis are reported in this paper.

The full table of correlation coefficients is not reproduced, but in case they might prove of interest to workers in related fields the correlations between the "social" variables are given in the Appendix.

\section{Results}

Our preliminary analysis had suggested that a substantial amount of the total variance would appear on the first two or three components but that subsequent components might be expected to reveal the inter-relationships of causes-of-death independent of the "social" variables. In the event it proved that much more variance was accounted for on the first few components than had been anticipated, primarily because of the nature of the data (Table II). The results of the analysis are not set out in extenso because, for reasons which are given later, we have confined outselves to a detailed discussion of two components (8 and 9) only. We, therefore, content ourselves with a brief indication of the first few components.
(1) The first principal component is obviously concerned with the size of population by age and accounts for 64.3 per cent. of the total variance. It removes, however, from 88 to 99 per cent. of the variance shown by each of the separate causes-ofdeath and 98 to 99 per cent. of the variance attributable to the age-size of population variables, but only a small amount (less than 5 per cent. in each case) of the variance of the other "social" variables.

TABLE II

DISTRIBUTION OF TOTAL VARIANCE ON SUCCESSIVE PRINCIPAL COMPONENTS

\begin{tabular}{c|c}
\hline Principal Component & Total Variance per Thousand \\
\hline 1 & $642 \cdot 6$ \\
2 & 115.0 \\
3 & $78 \cdot 2$ \\
4 & 51.4 \\
5 & 27.5 \\
6 & $22 \cdot 3$ \\
7 & $14 \cdot 5$ \\
8 & $10 \cdot 2$ \\
9 & $7 \cdot 2$ \\
10 & $5 \cdot 3$ \\
11 & $4 \cdot 6$ \\
12 & $4 \cdot 1$ \\
13 & $3 \cdot 2$ \\
14 & $2 \cdot 6$ \\
15 & $2 \cdot 2$ \\
$16-39$ & $9 \cdot 1$ \\
\hline
\end{tabular}


(2) The second principal component, which removes 11.5 per cent. of the total variance, is influenced mainly by birthplace, by education, and by density of population. In no instance does more than 1 per cent. of the variance due to any individual cause-of-death appear on this component.

(3)-(7) Principal components 3 to 7 together account for 19.4 per cent. of the total variance, showing small loadings for the causes-of-death but sizeable loadings due to past-overcrowding, social class, and birth-place.

(8)-(9) After the first principal component, appreciable loadings for the causes-of-death appear for the first time on principal Component 8 . For many of them even larger loadings appear on Component 9. These components are set out in full in
Table III. In absolute terms the loadings for the cause-of-death variables are, of course, small. The highest combined values are those for $J$, but even for this variable only 4.9 per cent. of the total variance shown by the original lymphosarcoma data appears on the two components 8 and 9. The original data were of course the actual number of deaths and, as has been indicated, the first principal component is concerned with age-size of population and, indeed, removes 98.7 per cent. of the variance of these four variables. We can therefore regard the residual correlations after the first component has been removed as being freed almost entirely from the influence of these factors. That is to say, the components from the second onwards have been to a large extent adjusted for age. In Table III, therefore, is shown for each cause-of-death the percentage of the variance remaining after the first component (or the age-adjusted variance) which appears on the

TABLE III

DISTRIBUTION OF VARIANCES

\begin{tabular}{|c|c|c|c|c|c|c|c|c|c|c|}
\hline \multirow[t]{2}{*}{ Symbol } & \multirow{2}{*}{\multicolumn{5}{|c|}{ Variable }} & \multicolumn{2}{|c|}{ Loadings on } & \multicolumn{3}{|c|}{$\begin{array}{l}\text { Percentage of Variance remaining after } \\
\text { P.C.1. which appears on Other Principal } \\
\text { Components }\end{array}$} \\
\hline & & & & & & P.C.8 & P.C.9 & P.C.2-7 & P.C. 8-9 & P.C.10-39 \\
\hline $\begin{array}{l}\mathbf{A} \\
\mathbf{B} \\
\mathbf{C} \\
\mathbf{D} \\
\mathbf{E} \\
\mathbf{F} \\
\mathbf{G} \\
\mathbf{H} \\
\mathbf{I} \\
\mathbf{J} \\
\mathbf{K} \\
\mathbf{L} \\
\mathbf{M} \\
\mathbf{N} \\
\mathbf{O} \\
\mathbf{P} \\
\mathbf{Q} \\
\mathbf{R} \\
\mathbf{S} \\
\mathbf{T} \\
\mathbf{U} \\
\mathbf{V}\end{array}$ & $\begin{array}{l}\text { Cancer of Oesopha } \\
\text { Cancer of Stomach } \\
\text { Cancer of Large In } \\
\text { Cancer of Rectum } \\
\text { Cancer of Pancreas } \\
\text { Cancer of Larynx } \\
\text { Cancer of Lung } \\
\text { Cancer of Bladder } \\
\text { Cancer of Bone } \\
\text { Lymphosarcoma } \\
\text { Hodgkin's Disease } \\
\text { Leukaemia ... } \\
\text { Respiratory Tuberc } \\
\text { Diabetes } \quad \ldots \\
\text { Vascular } \quad \ldots \\
\text { Coronary Disease } \\
\text { Pneumonia } \quad \ldots \\
\text { Bronchitis } \quad \ldots \\
\text { Ulcer ... } \quad \ldots \\
\text { Hypertension } \\
\text { Nephritis } \quad . . \\
\text { Prostate } \quad \ldots\end{array}$ & 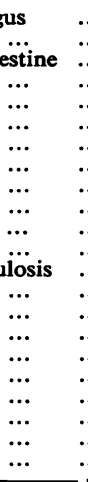 & $\begin{array}{l}\ldots . \\
\cdots \\
\cdots \\
\cdots \\
\cdots \\
\cdots \\
\cdots \\
\cdots \\
\cdots \\
\cdots \\
\cdots \\
\cdots \\
\cdots \\
\cdots \\
\cdots \\
\cdots \\
\cdots \\
\cdots\end{array}$ & $\begin{array}{l}\ldots . \\
\cdots \\
\cdots \\
\cdots \\
\cdots \\
\cdots \\
\cdots \\
\cdots \\
\cdots \\
\cdots \\
\cdots \\
\cdots \\
\cdots \\
\cdots \\
\cdots \\
\cdots \\
\cdots \\
\cdots \\
\cdots\end{array}$ & $\begin{array}{l}\ldots . \\
\cdots \\
\cdots \\
\cdots \\
\cdots \\
\cdots \\
\cdots \\
\cdots \\
\cdots \\
\cdots \\
\cdots \\
\cdots \\
\cdots \\
\cdots \\
\cdots \\
\cdots \\
\cdots \\
\cdots \\
\cdots\end{array}$ & $\begin{array}{r}-0.015 \\
0.062 \\
0.031 \\
0.020 \\
-0.016 \\
-0.040 \\
-0.113 \\
-0.040 \\
0.128 \\
-0.118 \\
0.023 \\
-0.051 \\
-0.020 \\
0.073 \\
0.081 \\
0.012 \\
-0.063 \\
0.010 \\
-0.052 \\
-0.035 \\
0.105 \\
0.006\end{array}$ & $\begin{array}{r}0.007 \\
-0.105 \\
-0.077 \\
-0.028 \\
0.047 \\
0.048 \\
0.129 \\
0.045 \\
-0.150 \\
0.186 \\
0.054 \\
0.105 \\
0.010 \\
-0.136 \\
-0.125 \\
-0.024 \\
0.093 \\
-0.028 \\
0.056 \\
0.035 \\
-0.171 \\
-0.033\end{array}$ & $\begin{array}{r}6 \cdot 7 \\
21 \cdot 7 \\
20 \cdot 5 \\
4 \cdot 2 \\
7.9 \\
19 \cdot 0 \\
30 \cdot 8 \\
12.4 \\
12 \cdot 3 \\
14 \cdot 3 \\
5 \cdot 7 \\
8 \cdot 3 \\
30.8 \\
11.9 \\
18 \cdot 0 \\
14 \cdot 1 \\
18 \cdot 5 \\
40.1 \\
23.1 \\
12.7 \\
15.6 \\
28.5\end{array}$ & $\begin{array}{r}1 \cdot 0 \\
47 \cdot 8 \\
36 \cdot 6 \\
7 \cdot 8 \\
10 \cdot 1 \\
7 \cdot 4 \\
48 \cdot 4 \\
14 \cdot 8 \\
51 \cdot 1 \\
44 \cdot 3 \\
4 \cdot 7 \\
27 \cdot 0 \\
0 \cdot 6 \\
45 \cdot 3 \\
58 \cdot 7 \\
6 \cdot 0 \\
31 \cdot 0 \\
1 \cdot 4 \\
26 \cdot 0 \\
8 \cdot 4 \\
56 \cdot 7 \\
2 \cdot 1\end{array}$ & $\begin{array}{l}92 \cdot 3 \\
30.4 \\
42.9 \\
88.0 \\
82.0 \\
73.6 \\
20 \cdot 8 \\
72 \cdot 8 \\
36.6 \\
41 \cdot 4 \\
89.6 \\
64 \cdot 7 \\
68.6 \\
42.8 \\
23 \cdot 3 \\
79.9 \\
50.5 \\
58 \cdot 5 \\
50.9 \\
79.9 \\
27 \cdot 7 \\
69.4\end{array}$ \\
\hline $\begin{array}{l}\mathbf{a} \\
\mathbf{b} \\
\mathbf{c} \\
\mathbf{d}\end{array}$ & Age Size of Popula & ion (yrs) & $\begin{array}{l}55 \\
65 \\
75 \\
85\end{array}$ & $\begin{array}{l}\cdots \\
\cdots \\
\cdots\end{array}$ & $\begin{array}{l}\cdots \\
\cdots \\
\cdots\end{array}$ & $\begin{array}{r}-0.012 \\
0.003 \\
0.003 \\
0.019\end{array}$ & $\begin{array}{r}0.056 \\
0.022 \\
0.007 \\
-0.026\end{array}$ & $\begin{array}{r}3 \cdot 8 \\
0 \cdot 0 \\
0 \cdot 7 \\
26 \cdot 2\end{array}$ & $\begin{array}{r}20 \cdot 4 \\
0.5 \\
0 \cdot 1 \\
5 \cdot 4\end{array}$ & $\begin{array}{l}75 \cdot 8 \\
99 \cdot 5 \\
99 \cdot 2 \\
68 \cdot 5\end{array}$ \\
\hline f & $\begin{array}{l}\text { Density } \\
\text { Past Overcrowding }\end{array}$ & $\cdots$ & $\cdots$ & 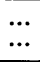 & $\begin{array}{l}\cdots \\
\cdots\end{array}$ & $\begin{array}{l}-0.152 \\
-0.097\end{array}$ & $\begin{array}{l}-0.064 \\
-0.123\end{array}$ & $\begin{array}{l}89 \cdot 6 \\
92 \cdot 4\end{array}$ & $\begin{array}{l}2 \cdot 9 \\
1 \cdot 5\end{array}$ & $\begin{array}{l}7 \cdot 5 \\
6 \cdot 1\end{array}$ \\
\hline h & Social Class & & $\begin{array}{l}\cdots \\
\cdots \\
\cdots\end{array}$ & $\begin{array}{l}\cdots \\
\cdots \\
\cdots\end{array}$ & $\begin{array}{l}\cdots \\
\cdots \\
\cdots\end{array}$ & $\begin{array}{r}-0.267 \\
0.195 \\
0.070\end{array}$ & $\begin{array}{r}-0.093 \\
0.001 \\
0.098 \\
\end{array}$ & $\begin{array}{l}90 \cdot 0 \\
95 \cdot 3 \\
97 \cdot 8 \\
\end{array}$ & $\begin{array}{l}8 \cdot 0 \\
3 \cdot 8 \\
1 \cdot 5 \\
\end{array}$ & $\begin{array}{l}2.0 \\
0.9 \\
0.7\end{array}$ \\
\hline $\mathbf{j}$ & Education & $\cdots$ & $\cdots$ & $\cdots$ & $\cdots$ & $0 \cdot 108$ & -0.030 & $89 \cdot 5$ & $1 \cdot 3$ & $9 \cdot 1$ \\
\hline $\begin{array}{l}\mathbf{k} \\
\mathbf{l} \\
\mathbf{m} \\
\mathbf{n} \\
\mathbf{0} \\
\mathbf{p} \\
\mathbf{q}\end{array}$ & $\begin{array}{l}\text { Place of } \\
\text { Birth }\end{array}$ & $\begin{array}{l}\text { gland } \\
\text { les } \\
\text { talnd } \\
\text { Ireland } \\
\text { mmonwe } \\
\text { reign }\end{array}$ & $\begin{array}{l}\cdots \\
\cdots \\
\cdots \\
\ldots \\
\text { realth } \\
\cdots\end{array}$ & $\begin{array}{l}\ldots \\
\ldots \\
\ldots \\
\ldots \\
\cdots \\
\cdots\end{array}$ & $\begin{array}{l}\ldots \\
\ldots \\
\ldots \\
\ldots \\
\ldots \\
\cdots\end{array}$ & $\begin{array}{r}-0.061 \\
0.027 \\
0.112 \\
-0.168 \\
-0.035 \\
0.019 \\
0.327\end{array}$ & $\begin{array}{r}-0.028 \\
0.011 \\
0.121 \\
-0.140 \\
0.007 \\
0.016 \\
0.105\end{array}$ & $\begin{array}{l}98 \cdot 8 \\
99 \cdot 7 \\
95 \cdot 0 \\
89 \cdot 8 \\
88 \cdot 9 \\
88 \cdot 4 \\
81 \cdot 2\end{array}$ & $\begin{array}{r}0 \cdot 5 \\
0 \cdot 1 \\
2 \cdot 7 \\
4 \cdot 8 \\
0 \cdot 1 \\
0 \cdot 1 \\
11 \cdot 9\end{array}$ & $\begin{array}{r}0.7 \\
0.2 \\
2.3 \\
5.4 \\
10.9 \\
11.5 \\
6.9\end{array}$ \\
\hline
\end{tabular}


subsequent components. It will be seen that this fraction varies on the 8th and 9th components from 0.6 per cent. (for respiratory tuberculosis) to 58.7 per cent. (for vascular lesions of the central nervous system). For all the 22 causes-of-death the mean amount of the age-adjusted variance appearing on these two components combined is 24.4 per cent., whereas the six components 2 to 7 have a mean age-adjusted variance of 2.85 per cent. per variable per component. It is thus clear that these two components are making an important contribution to the age-adjusted variance of several of the causes-ofdeath.

(10)-(39) After the ninth component, only $3 \cdot 1$ per cent. of the total variance of all the variables remains to be accounted for. This is distributed over the remaining thirty components (from 10 to 39 ). The amount that appears on any one component is therefore small, so that a detailed consideration does not seem to be warranted. Even if these components proved to be statistically significant (a question over which there is a formal difficulty) they cannot be of practical importance.

If we examine the distribution of the age-adjusted variance, i.e. that remaining after the first principal component, in Table III as between the three groups of principal components $(2-7,8$ and $9,10-39)$ we find that for most of the "social" variables the first group (Components 2-7) accounts for the major fraction, while Components 8 and 9 account for only small amounts. The cause-of-death variables, however, present a different picture, and for seven of them (cancer of the stomach, lung, bone, lymphosarcoma, diabetes, vascular lesions of the central nervous system, and nephritis) more variance appears on these two components than on either of the other two groups of components. In other words, these two components ( 8 and 9) represent for these causes-of-death important determinants of the variation in mortality shown by them from area to area. For nine causes of death (cancer of oesophagus, rectum, larynx, Hodgkin's disease, respiratory tuberculosis, coronary disease, hypertensive heart disease, bronchitis, and benign enlargement of the prostate) less than one-tenth of their age-adjusted variance appear on these two components. For these nine causes, therefore, these components are unimportant determinants of the variation from area to area in the level of mortality.

As has been stated, Components 2-7 are heavily loaded with the "social" variables of density of population, past-overcrowding, social class, education, and birth place. It will be seen that for lung cancer and tuberculosis 30 per cent., and for bronchitis 40 per cent., of the age-adjusted variance is extracted by these components. By contrast, these components account for less than 10 per cent. of the variance (remaining after the first component) for such causes-of-death as cancer of oesophagus, rectum and pancreas, Hodgkin's disease, and leukaemia. This implies that, for these latter causesof-death, urbanization, social class, etc., are relatively unimportant in determining the variation in mortality rates from area to area.

Technically, Components 8 and 9 are bipolar and we would therefore expect the "specific" factors for the different causes-of-death to emerge at a subsequent stage in the analysis, i.e. somewhere on Components 10 to 39 . For the reasons already stated, we do not consider our data will allow us satisfactorily to examine these "specific" factors.

\section{INTERPRETATION OF COMPONENTS 8 AND 9}

There are two kinds of evidence which may assist in ascribing a "meaning" to a factor that emerges in an analysis of this nature.

In the first place it may be that the internal evidence of the analysis itself will supply a clue. For example, our first principal component accounts for 98-99 per cent. of the variance due to the "age-size" variables. Very large amounts of the variance for every cause-of-death appear on this component and, as our basic data were the number of deaths from different causes in the different areas, this is the expected result if we equate this first component with an "age-size of population" factor.

The second kind of evidence is external to the analysis. It may be that the configuration revealed in the analysis is recognized on the basis of collateral information as being similar to that shown by some variable which was not itself included in the analysis. The more closely the two pictures coincide the more likely it is that the "external" variable is being represented by the factor in question. If the internal evidence of the analysis also supports this identification, the conclusion is, of course, strengthened.

Components 8 and 9 are obviously closely related because the order in which the causes-of-death are ranked are very similar, the ranking order on the one being in fact almost exactly the reverse of that on the other. The relationships of the variables in the plane defined by these two components (which are orthogonal to each other) is shown in Fig.2(opposite). 


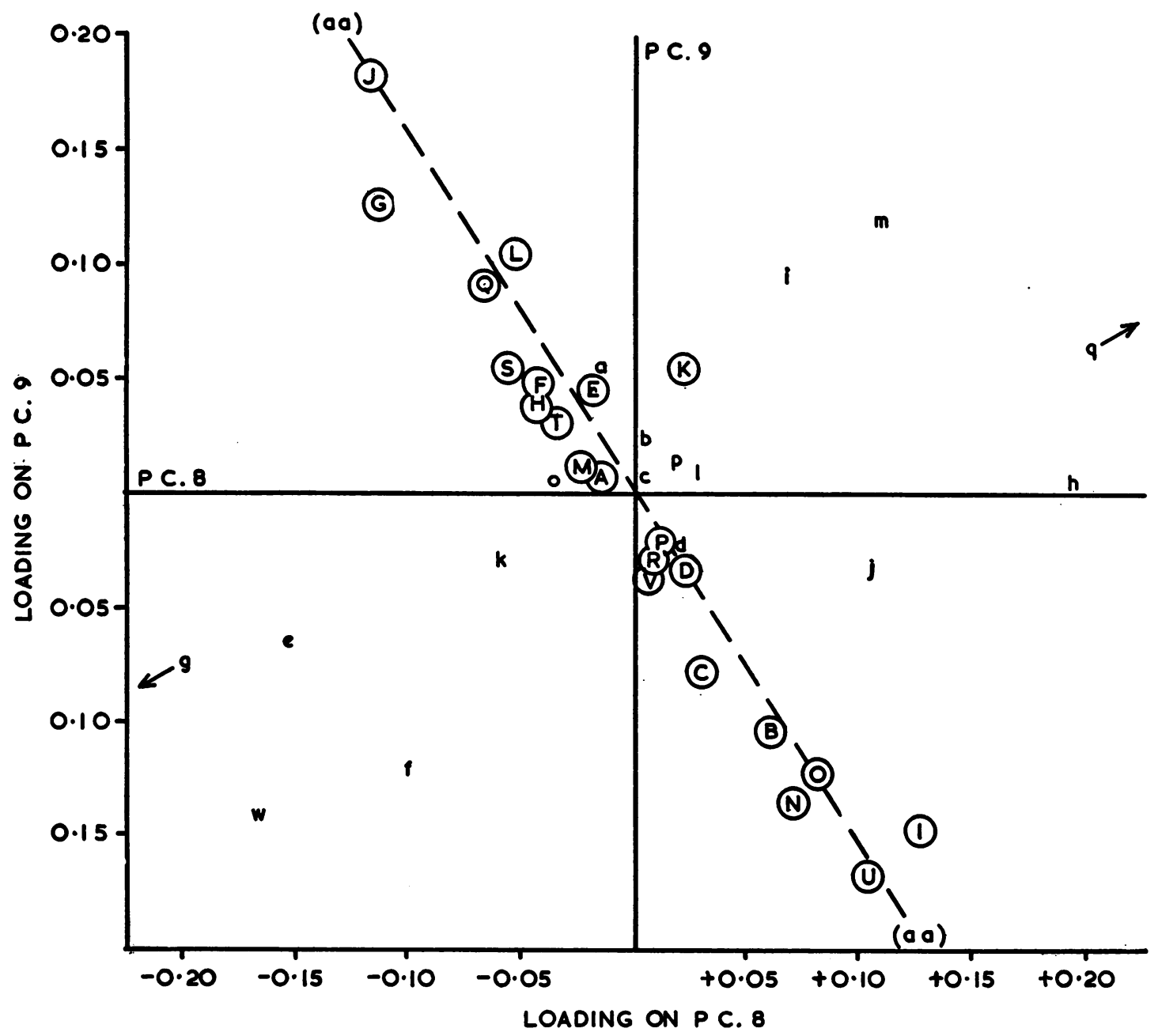

FIG. 2.-Position of variables relative to Principal Components 8 and 9 (For interpretation of symbols—see Table I).

It will be seen that the causes-of-death fall close to a straight line ( $a a-a a$ in the figure), with cancer of the bone, nephritis, vascular central nervous system lesions, diabetes, and gastric cancer at one end of the line, and leukaemia and pneumonia at the other.

We suggest that this order of ranking reflects in some way the diagnostic precision which can be attributed to the cause-of-death rubric. This "factor" of diagnostic precision would then be represented by a line (such as $a a-a a$ ) compounded of Components 8 and 9 , each of which separately measures some aspect, unidentified, of diagnostic precision.
We offer three pieces of collateral evidence in support of this interpretation:

(1) It is recognized that mortality data based on death certificates are to a greater or lesser extent fallible for a variety of reasons. One would expect the degree of fallibility to vary from cause to cause, from age group to age group, and from area to area. Table IV (overleaf), with data extracted from Stocks (1958), shows these features.

It seems likely that accuracy in certification will increase to the extent to which a diagnosis follows 
TABLE IV

BASIS OF DIAGNOSIS ACCORDING TO AGE AND AREA

Percentage of deaths in each group where diagnosis rested on post mortem, operation, or biopsy (after Stocks, 1958).

\begin{tabular}{|c|c|c|c|c|}
\hline \multirow{2}{*}{\multicolumn{2}{|c|}{ Cause }} & \multirow{2}{*}{ Area } & \multicolumn{2}{|c|}{ Age Group (yrs) } \\
\hline & & & $45-64$ & $\begin{array}{l}75 \text { and } \\
\text { Over }\end{array}$ \\
\hline Cancer of Stomach & $\ldots$ & \begin{tabular}{|l|} 
North Wales $\ldots .$. \\
County Boroughs \\
(excluding Liverpool)
\end{tabular} & $\begin{array}{l}65 \\
67\end{array}$ & $\begin{array}{l}15 \\
28\end{array}$ \\
\hline Cancer of Intestine & $\ldots$ & $\begin{array}{l}\text { North Wales ... } \\
\text { County Boroughs }\end{array}$ & $\begin{array}{l}76 \\
88\end{array}$ & $\begin{array}{l}29 \\
44\end{array}$ \\
\hline $\begin{array}{c}\text { Cancer of Liver and } \\
\text { Pancreas } \quad \ldots\end{array}$ & $\ldots$ & $\begin{array}{l}\text { North Wales ... } \\
\text { County Boroughs }\end{array}$ & $\begin{array}{l}72 \\
88\end{array}$ & $\begin{array}{l}20 \\
52\end{array}$ \\
\hline Cancer of Lung & $\ldots$ & $\begin{array}{l}\text { North Wales } \ldots . . \\
\text { County Boroughs }\end{array}$ & $\begin{array}{l}42 \\
51\end{array}$ & $\begin{array}{l}15 \\
26\end{array}$ \\
\hline
\end{tabular}

an autopsy. The Registrar General has published an analysis of all deaths occurring during the second quarter of 1953, showing for each cause-of-death the proportion certified after post mortem examination (Registrar General, 1956).*

There are eighteen causes-of-death common to both the 1953 analysis and to our present list. The percentage of deaths certified after post mortem examination for these eighteen causes-of-death correlate significantly with the rankings both of principal Component 8 and principal Component 9. The rank-order correlation coefficients (Spearman) are respectively $-0.55(p$ close to 0.01$)$ and +0.59 ( $p$ less than 0.01).

(2) Even when the death occurs in hospital there may be substantial disagreement in the case of several diseases between the diagnosis made on clinical grounds and the post mortem findings. In an investigation conducted during part of 1955, a special form of death certificate was used in ten selected hospitals on which both the ante and post mortem diagnoses were entered. It was found that, in half the deaths, there was a lack of agreement between the two certificates which would frequently have involved attributing the death to a different rubric (Registrar General, 1958). This point is further discussed later. Each of the 22 causes-ofdeath used in our analysis appear also in the list used by the Registrar General. For two of these, however, (cancer of the larynx and cancer of bone)

* A more extensive analysis published by him for 1954 (Registrar General, 1957) is not suitable for our purposes as the grouping of causes-of-death is in some instances, e.g. malignant disease of the digestive tract, too broad. only three cases confirmed at post mortem were recorded in the Registrar General's series. These two causes-of-death have therefore been omitted from the comparison that follows. If we accept the post mortem findings as the "true" cause-of-death, it is possible from the data given to assess the extent of over-diagnosis and under-diagnosis when clinical findings only are taken into account. Thus, cancer of the lung was diagnosed clinically in 61 cases but found at post mortem in 79 cases-a degree of underdiagnosis amounting to 23 per cent.- while cancer of the stomach was diagnosed clinically in 32 cases but only confirmed by post mortem in 24 cases-an over-diagnosis rate of 33 per cent. When the twenty causes-of-death are ranked according to the percentage agreement between clinical and post mortem findings in this way, there is a significant degree of correlation with the ranking shown both on principal Component 8 and principal Component 9. The rank-order correlation coefficients (Spearman) are respectively $+0.56(p$ less than 0.01$)$ and $-0.55(p$ less than 0.01).

(3) In a survey covering ten metropolitan areas in the United States, the site of malignant disease as stated on the death certificate was available for comparison with the site as recorded in the case report in a total of 22,681 deaths which occurred during 1947-1949 (Dorn and Cutler, 1959). The percentage of death certificates which were "correct" in the sense that the site of the disease agreed with that recorded in the case report varied from $48 \cdot 3$ per cent. for cancer of bone to 96.9 per cent. for leukaemia. It is possible to compare twelve sites of malignant disease in this report with the same sites in our analysis, and when these twelve sites are ranked according to the percentage of cases in which the diagnosis on the death certificate agreed with that on the case report there is a correlation (Spearman) of -0.40 against the ranking on principal Component 8 , and of +0.33 against the ranking on principal Component 9. These correlations do not quite achieve the conventional level of significance. There are two causes-of-death (cancer of the stomach and lymphosarcoma) which occupy anomalous positions, and if these are eliminated highly significant correlations are obtained for the remaining ten causes-of-death $(-0.84$ on principal Component 8 and +0.79 on principal Component 9; both are significantly beyond the 0.01 level). In the same study the percentage is given of deaths (excluding deaths which came to notice only as the result of death certificates) in which the diagnosis was 
supported by microscopical examination. When the twelve body sites incorporated in our analysis are compared with these percentages, there is a correlation (Spearman) of +0.50 with the ranking on principal Component 9. This is not quite significant at the 0.05 level, but if cancer of lung which occupies an anomalous rank is excluded the correlation increases to +0.73 ( $p$ less than 0.01 ) for the remaining eleven body sites. When it is considered that the ten metropolitan areas were all large cities each with a medical school, whereas we are dealing with the whole of England and Wales, it is remarkable that such a degree of agreement should be noted between our variables and the two indices of diagnostic accuracy quoted above.

We consider that the internal evidence of the analysis itself is also consistent with this interpretation of the factor reflected in principal Components 8 and 9 for the following reasons:

(a) Respiratory tuberculosis and cancer of the oesophagus have very small loadings on both components. Bronchitis and benign enlargement of the prostate also show small percentage variances on these components. This implies that these are causesof-death for which diagnostic criteria show the greatest degree of uniformity from area to area. On clinical grounds, this conclusion would seem reasonable.

(b) That the diagnostic basis for certification of cancer of the stomach, large intestine, and lung may vary from area to area is indicated in Table IV. All these causes have sizeable variances appearing on these two components. Furthermore, from the data on which Table IV is based, it appears that the variances between areas of malignant disease of stomach and large intestine are larger than that of lung. This is in accord with the relative positions of these variables on the line $a a-a a$ in Fig. 2.

(c) Lymphosarcoma, diabetes, vascular lesions of the central nervous system, and nephritis and nephrosis-all of which have large percentage variances on these two components-are conditions in which accuracy of diagnosis might well vary from area to area as a consequence of differing facilities or nosological preferences. A diagnosis of leukaemia, lymphosarcoma, or Hodgkin's disease is usually made following a laboratory procedure, while cancer of the larynx, pancreas, and bladder, and ulcer of the stomach and duodenum, would often be diagnosed at operation with, in many cases, biopsy. The extent to which these aids to diagnostic precision were available or were utilized may well have varied appreciably in different parts of the country in the first years of the operation of the National Health Service.

(d) Although most of the variance due to age has been extracted on the first principal component, a certain amount appears on Components 8 and 9. The alignment of the "age-size" variables relative to the line $a a-a a$ in Fig. 2 is the one we should expect if this line represented some aspect of diagnostic precision. A precise diagnosis is more likely in a man aged 55-64 years than in a man aged 85 years or over.

(e) Most of the other social variables seem to be un-related to this factor as judged by their relationship to the line $a a-a a$ in Fig. 2. This suggests that the diagnostic precision factor is not unduly influenced by the degree of urbanization, the social class structure or the racial background of an area. At first sight this might appear anomalous in that facilities for accurate diagnosis might be expected to be related to these characteristics of local populations. It should be pointed out, however, that the major part of the variance due to these variables has already been removed (on principal Components 2-7). What we find on principal Components 8 and 9 is a factor, here thought to be related to diagnostic precision, which is virtually independent of population density, social class, and the rest. This is not to say that included in the complex of influences represented, say, by the single variable "density of population" there may not also be an element of diagnostic precision. We cannot say. What we can say is that, even after the effect of this complex of influences has been largely eliminated, there still remains this factor which we think represents diagnostic accuracy.

\section{Discussion}

It would appear that the interpretation which we put forward for our principal Components 8 and 9 carries an important implication as regards statistical work on mortality data. It is obvious that, where different causes-of-death show such marked differences in the proportion of age-adjusted variance which is associated with these two components, difficulties will arise in seeking to deal with their geographical patterns of distribution of mortality as if causes-of-death were homogeneous sets of variables. It would seem that for some conditions 
(respiratory tuberculosis, bronchitis, cancer of the oesophagus, Hodgkin's disease, and benign enlargement of the prostate) the geographical pattern as it stands might be taken to represent a "true" distribution of mortality. For other conditions, however, (notably cancer of the stomach and of bone, nephritis, vascular lesions of the central nervous system, lymphosarcoma, leukaemia, pneumonia, and cancer of the lung) this is not so. When the geographical pattern of mortality from any of these causes is considered, it would be necessary to bear in mind that as much as half the variance displayed in the age-adjusted rates may in fact be due to differences in diagnostic precision as between areas.

If our hypothesis is correct it would seem that cancer of bone was being over-diagnosed to a variable extent in different parts of the country. It is relevant that, in the ten metropolitan areas study referred to above, cancer of bone was the form of malignant disease which showed the highest percentage of over-diagnosis of all the body sites, when death certificates were compared with case reports. It would seem, too, that leukaemia and pneumonia are two conditions which are being under-diagnosed to a variable extent in different areas.

So far as we are aware, there has been only one other attempt to apply the methods of factor analysis to mortality data. Buckatzsch and Doll (1952) analysed the mortality from malignant disease of ten body sites in thirty large towns in England and Wales during the period 1920-1931, using Hotelling's method of principal components. They found that more than three-quarters of the total variance appeared on the first four factors. Comparison of their results with those of our analysis is not straightforward because there are only seven causes-ofdeath in common. There does not appear, however, to be any resemblance between the factors they extracted and the factor of diagnostic precision represented by our components 8 and 9 . This is not unexpected for three reasons:

(1) The considerable difference in the periods dealt with in the two analyses;

(2) The fact that they dealt only with large cities, where more homogeneity of diagnostic accuracy might be expected than when, as in our case, the the whole country is under review;

(3) Possibly most important of all, the fact that they confined themselves to the age group 45-64 years, whereas our data referred to all ages.
The diagnostic validity of death certificates has been considered by several writers. Pohlen and Emerson (1943) compared the clinical and post mortem statements on the cause-of-death for some 25,000 deaths in United States hospitals during the years 1930-1939. It was found that the clinical statement was accurate in the sense of being supported by the post mortem findings in 96 per cent. of deaths from respiratory tuberculosis, in 94 per cent. from leukaemia, but in only 87 and 79 per cent. respectively from gastric cancer and diabetes. James, Patton, and Heslin (1955) reviewed all the autopsied deaths during 1951-1952 in twelve hospitals in the Albany area of New York State. A form of death certificate was completed in each case after scrutiny of the clinical records and autopsy reports. The coded entry on this certificate was then compared with that on the official certificate which had been issued originally on the death of the patient. The percentage of cases showing agreement between the two certificates varied from 93.8 per cent. for tuberculosis (all forms) to 30.6 per cent. (for diabetes), 52.0 per cent. for nephritis, and 59.5 per cent. for vascular lesions of the central nervous system. Benign enlargement of the prostate ( 83.3 per cent.) and coronary disease $(\mathbf{7 2} \cdot 8$ per cent.) showed higher rates of agreement. Comparison with our data is not possible because deaths from certain causes are selectively autopsied. McKenzie (1956) investigated by questionnaire the diagnostic techniques employed in a random sample of deaths in England and Wales certified as cancer of either lung or stomach. The diagnosis was regarded as "unsupported" in 3.2 per cent. of all deaths attributed to lung cancer and in 8.4 per cent. of male deaths and 18 per cent. of female deaths attributed to gastric cancer. The proportion of certificates with "unsupported" diagnoses for both causes-of-death increased with age. In a study conducted in Pennsylvania, the death certificates of a sample of 1,837 deaths occurring during 1956 were reviewed (Moriyama, Baum, Haenszel and Mattison, 1958). Detailed comparison with our own data is not possible because the Pennsylvania sample contained both men and women and what the authors refer to as "diagnostic quality" was not independent of sex for certain numerically important causes-of-death. In addition, the categories employed by them do not correspond in many cases with our own. Nevertheless, some of their findings show interesting parallels with those reported in this paper. They found, for example, that the quality of the information on which the death certificate was completed varied with the cause-ofdeath. They state that "the diagnostic evidence for malignant neoplasms appears weakest for stomach 
and pancreas", but that the diagnosis was well supported for malignant disease of the larynx and urinary organs, leukaemia, and lymphosarcoma. The diagnosis was considered to be "solidly established" in only 50 per cent. of cases of diabetes and 31.8 per cent. of cases of vascular lesions of the central nervous system. It was also found that "the quality of diagnosis falls off for deaths at the older ages". Within the state of Pennsylvania it was noted that diagnostic quality was higher in urban than in rural practices.

Acheson (1960), having studied the pattern of mortality in the Republic of Ireland and in certain other countries, concluded that a high mortality rate from coronary disease and hypertension partly, at all events, reflects the standard of diagnosis and certification. He states that "variations in diagnostic and statistical technique cannot be ruled out as an important contributory factor" in the differences noted in the mortality rates from cerebral vascular accidents.

Initially, we undertook this factor analysis to see if some unsuspected relationships between causes-ofdeath might not come to light. If, for example, it was found that three causes-of-death- $a, b$, and $c-$ showed a close relationship on one or more factors, and if it was known from other work that $a$ and $b$, say, were influenced by some environmental element (occupation, diet, housing, etc.) this would suggest that $c$ might also be influenced by this element. We have not been able to carry our analysis as far as this stage. It is clear however, that subsequent work on these lines will need to take the factor of diagnostic precision into account. It seems likely that the effect of such a factor would be minimized if deaths at younger ages rather than deaths at all ages were made the subject of particular study.

\section{SUMmary}

(1) An account is given of a factor analysis of the mortality experience of males in England and Wales during 1950-1953, using the method of principal components.

(2) For several causes-of-death, an important determinant of the level of recorded mortality is a factor which appears to represent diagnostic precision.

(3) About half the age-adjusted variance as between administrative areas for five causes-ofdeath (malignant disease of stomach, of lung, and of bone, vascular lesions of the central nervous system, and nephritis and nephrosis) could on this interpretation be due to differences from area to area in the extent to which these diseases were over- or underdiagnosed at that time.

(4) For other causes-of-death (cancer of oesophagus, Hodgkin's disease, respiratory tuberculosis, bronchitis, and benign enlargement of prostate), this factor accounts for less than one-twentieth of the age-adjusted variance.

(5) The implications of these findings are discussed.

The diagrams were prepared by kind permission of the County Planning Officer (N. Sq. Johnson, Esq.) Anglesey County Council.

\section{REFERENCES}

Abbatt, J. D., and Lea, A. J. (1957). Lancet, 2, 917.

Acheson, R. M. (1960). Brit. J. prev. soc. Med., 14, 139. Buckatzsch, J., and Doll, R. (1952). J. Hyg., 50, 384.

Dorn, H. F., and Cutler, S. J. (1959). "Morbidity from Cancer in the United States". Public Health Monograph No. 56. U.S. Dept. of Health, Education and Welfare, Washington.

Dungal, N., and Benediktsson, T. (1958). Lancet, 1, 931. Elkeles, A. (1957). Ibid., 2, 714.

Hotelling, H. (1933). J. educ. Psychol., 24, 417, 498.

James, G., Patton, R. E., Heslin, A. S. (1955). Publ. Hlth Rep. (Wash.), 70, 39.

Krasnow, S. (1955). Personal communication.

McKenzie, A. (1956). Brit. med. J., 2, 204.

Moriyama, I. M., Baum, W. S., Haenszel, W. M., Mattison, B. F. (1958). Amer. J. publ. Hlth, 48, 1376.

Pohlen, K., and Emerson, H. (1943). Ibid., 33, 505.

Registrar General (1956). Statistical Review of England and Wales for 1953, Text Volume. H.M.S.O. (1957). Statistical Review of England and Wales for 1954. Pt. 3. Commentary. H.M.S.O.

(1958). Statistical Review of England and Wales for 1956. Pt. 3. Commentary. H.M.S.O.

Stocks, P. (1958). British Empire Cancer Campaign 35th Annual Report, 1957. Supplement to Part II London.

(1959). Brit: med.J., 1, 74.

Thurstone, L. L. (1947). "'Multiple-Factor Analysis". University of Chicago Press, Chicago.

Vernon, P. E. (1958). Personal communication.

Watkinson, G. (1958). Gastroenterologia (Basel), 89, 292.

See Appendix (overleaf) 
APPENDix TABLE

CORRELATION COEFFICIENTS OF "SOCIAL" VARIABLES

(For interpretation of symbols see Table I)

\begin{tabular}{|c|c|c|c|c|c|c|c|c|c|c|c|c|c|c|c|c|}
\hline & b & c & d & e & f & g & h & i & $\mathrm{j}$ & $\mathrm{k}$ & 1 & $\mathrm{~m}$ & $\mathbf{n}$ & o & p & $q$ \\
\hline$a$ & 9956 & 9930 & 9803 & -1982 & -1634 & 0568 & 0905 & -1456 & -0242 & 1057 & -0936 & -0142 & -0365 & -0257 & -0567 & -0867 \\
\hline b & & 9956 & 9871 & -2163 & -1705 & 0603 & 0839 & -1420 & -0286 & 1002 & -0848 & -0257 & -0509 & -0480 & -0699 & -1004 \\
\hline c & & & 9898 & -2180 & -1744 & 0802 & 0732 & -1526 & -0215 & 0943 & -0797 & -0235 & -0597 & -0494 & -0611 & -0956 \\
\hline d & & & & -2508 & -1946 & 0995 & 0438 & -1432 & -0197 & 0993 & -0819 & -0263 & -0802 & -0819 & -0646 & -1053 \\
\hline e & & & & & 7074 & -2424 & 2146 & 0163 & 2155 & 1179 & -2261 & 2109 & 3778 & 6536 & 5541 & 4730 \\
\hline$f$ & & & & & & -4388 & 0428 & 4054 & -0420 & 0888 & -1370 & 1208 & 1413 & 2858 & 2757 & 1982 \\
\hline g & & & & & & & -5188 & -5549 & 6594 & -2985 & 2393 & 1614 & -0102 & 0701 & 3240 & 3107 \\
\hline $\mathrm{h}$ & & & & & & & & -4147 & -3520 & 4482 & -4266 & 1004 & 1693 & 0932 & -1166 & -1765 \\
\hline i & & & & & & & & & -4115 & -1163 & 1671 & -2852 & -1730 & -2001 & -2824 & -2018 \\
\hline $\mathbf{j}$ & & & & & & & & & & -2579 & 1050 & 3811 & 2969 & 5229 & 7636 & 7491 \\
\hline $\mathbf{k}$ & & & & & & & & & & & -9805 & 1691 & 0950 & -0169 & -0302 & -0748 \\
\hline 1 & & & & & & & & & & & & -2829 & -2141 & -1483 & -1494 & -1058 \\
\hline $\mathrm{m}$ & & & & & & & & & & & & & 5486 & 4098 & 4840 & 3508 \\
\hline $\mathrm{n}$ & & & & & & & & & & & & & & 6708 & 5359 & 3651 \\
\hline o & & & & & & & & & & & & & & & 7560 & 6614 \\
\hline $\mathbf{p}$ & & & & & & & & & & & & & & & & 7856 \\
\hline
\end{tabular}

